\title{
The IJTMB is endorsing the CARE Statement
}

Anthony Porcino, PhD, HSI, Executive Editor, IJTMB

\author{
CAMEO, UBC School of Nursing and BC Cancer Agency, Vancouver, BC, Canada
}

The value of writing and of publishing case reports in a profession has long been recognized; multiple articles explain the importance of case studies, ${ }^{(1,2)}$ and how to do them. ${ }^{(3-6)}$ However, having recommendations to publish case reports and in what to include in those reports doesn't automatically result in either a uniform approach to published reports, or inclusion of all appropriate or necessary information to make the case report valuable. Therefore, just as international groups have developed guidelines regarding the appropriate writing and publishing of manuscripts for clinical trials (CONSORT Statement), meta-analysis and systematic reviews (PRISMA Statement), and the Strobe Statement for observational studies, a similar effort has been done for case studies: the CARE Statement (www.care-statement.org).

The IJTMB will be endorsing the CARE Statement, and recommending the use of the framework for the writing, reviewing, and publishing of case reports. However, the IJTMB's Practice Section Editor and Editor-in-Chief rightfully recognized the limitations of the CARE Statement-developed generally for the health care field - with regard to specific issues in the practice of therapeutic massage and bodywork (TMB). The article in this issue by Munk and Boulanger is an important review of the CARE Statement from the perspective of TMB practice, and introduces a template for case reports specific to TMB practice and reporting. In addition to the template being highly recommended for publishing in the IJTMB (and hopefully for other physical manipulation health care practice journals), I hope that this work is taken to the next level: a formal TMB CARE Statement extension, much like the Non-Pharmacologic Treatment Interventions extension to the CONSORT Statement.
Only by ensuring that our case reports are including all the information needed can we ensure that the case reports have enduring value to-and impact on - the profession. These developments in international standards for case report publication are most welcome.

\section{COPYRIGHT}

Published under the CreativeCommons AttributionNonCommercial-NoDerivs 3.0 License.

\section{REFERENCES}

1. McEwen IR. Case reports: slices of real life to complement evidence. Phys Ther. 2004;84(2):126-127.

2. Munk N. Case reports: a meaningful way for massage practice to inform research and education. Int $J$ Ther Massage Bodywork. 2013;6(3):3-5.

3. Gleberzon BJ, Killinger LZ. The journal article cookbook. $J$ Manip Physiol Ther. 2004;27(7):481-92.

4. Budgell B. Guidelines to the writing of case studies. J Can Chiropr Assoc. 2008;52(4):194-204.

5. Hymel G. Research Methods for Massage and Holistic Therapies. St. Louis, NO: Elsevier Health Sciences; 2005.

6. Domholdt E. Physical Therapy Research. Philadelphia, PA: W.B. Saunders Company; 2000.

Corresponding author: Antony J. Porcino, BSc, PhD, HSI. CAMEO, UBC School of Nursing and BC Cancer Agency, T291 - 2211 Wesbrook Mall, Vancouver, BC, Canada V6T 2B5

E-mail: eeitjmb@gmail.com 